\title{
Effect of glucoraphanin and sulforaphane against chemotherapy-induced neuropathic pain: Kv7 potassium channels modulation by $\mathrm{H}_{2} \mathrm{~S}$ release in vivo
}

\author{
Elena Lucarini ${ }^{1}$ | Laura Micheli ${ }^{1}$ | Elena Trallori ${ }^{1}$ | Valentina Citi $^{2}$ | Alma Martelli ${ }^{2,3}$ | \\ Lara Testai ${ }^{2,3}$ (D) | Gina Rosalinda De Nicola ${ }^{4}$ | Renato lori ${ }^{4}$ | Vincenzo Calderone ${ }^{2,3}$ | \\ Carla Ghelardini ${ }^{1}$ । Lorenzo Di Cesare Mannelli (D)
}

\author{
${ }^{1}$ Department of Neuroscience, Psychology, \\ Drug Research and Child Health-Neurofarba- \\ Pharmacology and Toxicology Section, \\ University of Florence, Florence, Italy \\ ${ }^{2}$ Department of Pharmacy, University of Pisa, \\ Pisa, Italy \\ ${ }^{3}$ Interdepartmental Research Center \\ Nutrafood "Nutraceuticals and Food for \\ Health", University of Pisa, Pisa, Italy \\ ${ }^{4}$ Agricoltura e Ambiente (CREA-AA), Consiglio \\ per la Ricerca in Agricoltura e l'Analisi \\ dell'Economia Agraria, Bologna, Italy \\ Correspondence \\ Lorenzo Di Cesare Mannelli, Department of \\ Neuroscience, Psychology, Drug Research and \\ Child Health-Neurofarba-Pharmacology and \\ Toxicology Section, University of Florence, \\ Viale Pieraccini 6, Florence 50139, Italy. \\ Email: Iorenzo.mannelli@unifi.it \\ Funding information \\ Università degli Studi di Firenze; Università di \\ Pisa; Universities of Florence and Pisa; Italian \\ Ministry of Instruction, University and \\ Research (MIUR)
}

The beneficial effects of isothiocyanate-based compounds, as well as their safety, have been shown in neuropathological disorders, such as neuropathic pain. Aim of the present work was to study the efficacy of the glucosinolate glucoraphanin (GRA) and the derived isothiocyanate sulforaphane (SFN), secondary metabolites occurring exclusively in Brassicales, on chemotherapy-induced neuropathic pain. Mice were repeatedly treated with oxaliplatin $\left(2.4 \mathrm{mg} \mathrm{kg}^{-1} \mathrm{ip}\right)$ for 14 days to induce neuropathic pain. GRA and SFN effects were evaluated after a single administration on Day 15 or after a daily repeated oral and subcutaneous treatment starting from the first day of oxaliplatin injection until the $14^{\text {th }}$ day. Single subcutaneous and oral administrations of GRA (4.43-119.79 $\mu \mathrm{mol} \mathrm{kg}{ }^{-1}$ ) or SFN (1.33-13.31 $\mu \mathrm{mol} \mathrm{kg}{ }^{-1}$ ) reduced neuropathic pain in a dose-dependent manner. The repeated administration of GRA and SFN (respectively 13.31 and $4.43 \mu \mathrm{mol} \mathrm{kg}{ }^{-1}$ ) prevented the chemotherapyinduced neuropathy. The co-administration of GRA and SFN in mixture with the $\mathrm{H}_{2} \mathrm{~S}$ binding molecule, haemoglobin, abolished their pain-relieving effect, which was also reverted by pretreating the animals with the selective blocker of Kv7 potassium channels, XE991. GRA and SFN reduce neuropathic pain by releasing $\mathrm{H}_{2} \mathrm{~S}$ and modulating Kv7 channels and show a protective effect on the chemotherapy-induced neuropathy.

\section{KEYWORDS}

chemotherapy-induced neuropathic pain, glucoraphanin, $\mathrm{H}_{2} \mathrm{~S}$ donors, isothiocyanate, $\mathrm{Kv7}$ channels, sulforaphane

\section{I INTRODUCTION}

The discovery of new natural compounds with pharmacological properties is a field of interest widely growing, especially for the management of neuropathological conditions such as neuropathic pain, as often no pharmacological treatments effectively prevent or treat these

Abbreviations: AUC, area under the curve; GRA, glucoraphanin; $\mathrm{H}_{2} \mathrm{~S}$, hydrogen sulfide; Hb, haemoglobin; ITCs, isothiocyanates; MYR, myrosinase; PEG, polyethylene glycol; SFN, sulforaphane disorders (Cruccu \& Truini, 2017). Among the most studied phytochemicals there are the isothiocyanates (ITCs). Recently, synthetic and natural compounds with ITC-based structure have been demonstrated to have relevant pain-relieving properties in animal models of neuropathic pain (Di Cesare Mannelli et al., 2017). Natural ITCs derive from the hydrolysis of glucosinolates, a class of sulfur-containing secondary metabolites occurring exclusively in the botanical order Brassicales, including plants belonging to the family of Brassicaceae (Dinkova-Kostova \& Kostov, 2012). R-Sulforaphane (hereinafter 
referred to SFN) is the ITC released by the enzymatic action of plant-endogenous myrosinase ( $\beta$-thioglucoside glucohydrolase; E.C. 3.2.1.147; MYR) or by the microflora on glucoraphanin (GRA), a glucosinolate present especially in Tuscan black kale seeds (De Nicola, Rollin, Mazzon, \& lori, 2014). The interest in these phytochemicals escalated following the discovery of their cytoprotective properties against oxidative stress (Guerrero-Beltrána, Calderón-Oliver, Pedraza-Chaverri, \& Chirino, 2012). In the last years, beneficial effects of these compounds in models of neurological diseases, as well as their safety, have been shown (Galuppo et al., 2013; Giacoppo et al., 2014). In fact, like SFN, also other ITC-based compounds show protective effects in models of nervous tissue injury (Wang et al., 2012) and neuropathic pain development (Negi, Kumar, \& Sharma, 2011). Among the different mechanisms of action, which may account for the different biological effects of ITCs, the release of hydrogen sulphide $\left(\mathrm{H}_{2} \mathrm{~S}\right)$ has been recently reported: indeed, the ITC moiety was recognized as an original $\mathrm{H}_{2} \mathrm{~S}$-releasing chemical group (Martelli et al., 2014). Noteworthy, significant $\mathrm{H}_{2} \mathrm{~S}$-releasing properties have been also exhibited by many natural ITCs from Brassicaceae species, closely related with SFN, from a structural point of view (Citi et al., 2014). Consistently, the $\mathrm{H}_{2} \mathrm{~S}$ release and the activation of $\mathrm{Kv} 7$ potassium channels were demonstrated to be involved in the antihyperalgesic effect of ITC-based compounds (Di Cesare Mannelli et al., 2017). Although many of the health benefits showed by GRA and SFN are similar to that attributed to $\mathrm{H}_{2} \mathrm{~S}$ or other $\mathrm{H}_{2} \mathrm{~S}$-donating ITCs (Citi et al., 2014), the role of this gasotransmitter in their pharmacological effects needs to be further evaluated. This evidence could bring to light a new mechanism of action for these phytochemicals, which is not only attributable to their well-known antioxidative (Nrf2/ARE pathway; Xu et al., 2006) and anti-inflammatory proprieties (NF-kB pathway; Heiss, Herhaus, Klimo, \& Bartsch, 2001). The aim of the present study was to evaluate the effect of acute and repetitive GRA and SFN administrations on neuropathic pain induced by oxaliplatin in mice. In this contest, the pharmacodynamic involvement of $\mathrm{H}_{2} \mathrm{~S}$ and $\mathrm{Kv} 7$ potassium channels in their effect was investigated.

\section{I MATERIAL AND METHODS}

\subsection{Amperometric determination of $\mathrm{H}_{2} \mathrm{~S}$ release}

The evaluation of the potential $\mathrm{H}_{2} \mathrm{~S}$ releasing properties of GRA and SFN was carried out by an electrochemical approach with an Apollo4000 amperometric detector (WPI) and $\mathrm{H}_{2} \mathrm{~S}$-selective mini-electrodes, as previously described (Citi et al., 2014). Briefly, a "PBS buffer 10X" was previously prepared $\left(\mathrm{NaH}_{2} \mathrm{PO}_{4} \cdot \mathrm{H}_{2} \mathrm{O} 1.28 \mathrm{~g}, \mathrm{Na}_{2} \mathrm{HPO}_{4} \cdot 12 \mathrm{H}_{2} \mathrm{O}\right.$ $5.97 \mathrm{~g}, \mathrm{NaCl} 43.88 \mathrm{~g}$ in $500-\mathrm{ml} \mathrm{H}_{2} \mathrm{O}$ ) and stocked at $4^{\circ} \mathrm{C}$. For the experiments, the assay buffer was obtained by $1: 10$ dilution of the PBS buffer 10X with distilled water. The $\mathrm{pH}$ was adjusted to 7.4 The $\mathrm{H}_{2} \mathrm{~S}$-selective mini-electrode was immerged in 10-ml assay buffer at room temperature. After the recovery of a stable baseline, $100 \mu \mathrm{l}$ of a DMSO solution of GRA or SFN was added (the final concentration of the tested compounds was $1 \mathrm{mM}$; the final concentration of DMSO in the $A B$ was $1 \%$ ). The possible formation of $\mathrm{H}_{2} \mathrm{~S}$ was observed for 20 min. Preliminary measurements showed that DMSO 1\% did not interfere with the amperometric recording. In selected experiments, L-cysteine $(4 \mathrm{mM})$ was added before the addition of GRA or SFN. The relationships between the amperometric currents (detected in picoampere) and the matched concentrations of $\mathrm{H}_{2} \mathrm{~S}$ were evaluated by suitable calibration curves with the $\mathrm{H}_{2} \mathrm{~S}$-generating salt $\mathrm{NaHS}$ $(1,3,5$, and $10 \mu \mathrm{M})$ at $\mathrm{pH} 4.0$.

\section{2 | Animals}

Male CD-1 albino mice (Envigo, Varese, Italy) weighing approximately 22-25 $\mathrm{g}$ at the beginning of the experimental procedure were used. Animals were housed in CeSAL (Centro Stabulazione Animali da Laboratorio, University of Florence) and used at least 1 week after their arrival. Ten mice were housed per cage (size $=26 \times 41 \mathrm{~cm})$; animals were fed with a standard laboratory diet and tap water ad libitum and kept at $23 \pm 1^{\circ} \mathrm{C}$ with a 12-hr light/dark cycle, light at 7 a.m. All animal manipulations were carried out according to the Directive 2010/63/EU of the European parliament and of the European Union council (September 22, 2010) on the protection of animals used for scientific purposes. The ethical policy of the University of Florence complies with the Guide for the Care and Use of Laboratory Animals of the U.S. National Institutes of Health (NIH Publication No. 85-23, revised 1996; University of Florence assurance number: A5278-01). Formal approval to conduct the described experiments was obtained from the Animal Subjects Review Board of the University of Florence. Experiments involving animals have been reported according to ARRIVE guidelines (McGrath \& Lilley, 2015). All efforts were made to minimize animal suffering and to reduce the number of animals used.

\section{3 | Oxaliplatin-induced neuropathic pain models}

Mice treated with oxaliplatin $\left(2.4 \mathrm{mg} \mathrm{kg}^{-1}\right)$ were intraperitoneally administered on Days 1-2, 5-9, and 12-14 (10 ip injections; Cavaletti et al., 2001). Oxaliplatin was dissolved in $5 \%$ glucose solution. Control animals received an equivalent volume of vehicle. Behavioural tests were performed on Day 15 for the acute treatments, on Days 8 and 15 for the repeated administration protocol.

\section{4 | Compound administrations}

GRA and enantiopure $R$-SFN were purified from Tuscan black kale seeds at the Bologna laboratory (CREA-AA; previously CRA-CIN) according to an establish method (De Nicola et al., 2014). These compounds were dissolved in saline solution for subcutaneous (sc) administration and in carboxymethyl cellulose $1 \%$ for oral (po) administration. Compounds were acutely administered as follows. The doses of GRA were chosen on the basis of previously published $\mathrm{H}_{2} \mathrm{~S}$ releasing and antinociceptive properties of synthetic ITCs (Di Cesare Mannelli et al., 2017; Martelli et al., 2013): 4.43, 13.31, 39.93, and $119.78 \mu \mathrm{mol} \mathrm{kg}{ }^{-1}$ of GRA. The doses of SFN (1.33, 4.43, and $13.31 \mu \mathrm{mol} \mathrm{kg}{ }^{-1}$ ) were chosen from the doses of GRA found to be effective. Afterwards, repeated subcutaneous and oral administrations of GRA (13.31 $\left.\mu \mathrm{mol} \mathrm{kg}{ }^{-1}\right)$ and SFN (4.43 $\left.\mu \mathrm{mol} \mathrm{kg}{ }^{-1}\right)$ were carried out daily from the beginning to the end of oxaliplatin treatment. 
Behavioural tests were performed on Days 8 and 15, $24 \mathrm{hr}$ after the last administration.

In additional experiments, GRA (119.79 $\left.\mathrm{mmol} \mathrm{kg}^{-1}\right)$ and SFN

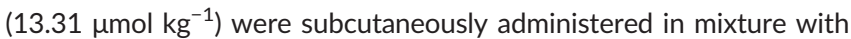
$3.10 \mu \mathrm{mol} \mathrm{kg}{ }^{-1}$ of human haemoglobin ( $\mathrm{Hb}$; Sigma-Aldrich, Italy) in saline solution, and behavioural tests were carried out after 15, 30, 45 , and $60 \mathrm{~min}$ from injection. The Kv7 potassium channel blocker XE991 (Tocris Bioscience, Italy; $7.98 \mu \mathrm{mol} \mathrm{kg}{ }^{-1} ; 1 \mathrm{mg} \mathrm{kg}$; Blackburn-Munro \& Jensen, 2003) was dissolved in saline solution and intraperitoneally administered $15 \mathrm{~min}$ before the injection of tested compounds.

\section{5 | Cold plate test}

The animals were placed in a stainless steel box $(12 \mathrm{~cm} \times 20 \mathrm{~cm} \times 10 \mathrm{~cm})$ with a cold plate as floor. The temperature of the cold plate was kept constant at $4^{\circ} \mathrm{C} \pm 1^{\circ} \mathrm{C}$. Pain-related behaviour (licking of the hind paw) was observed, and the time (seconds) of the first sign was recorded. The cut-off time of the latency of paw lifting or licking was set at 60 s (Di Cesare Mannelli, Maresca, Farina, Scherz, \& Ghelardini, 2015). The results were expressed either by the licking latency or by the area under the curve (AUC) resulting from the compounds acute administration.

\subsection{Statistical analysis}

The curves relative to the progressive increase of $\mathrm{H}_{2} \mathrm{~S}$ versus time, following the incubation of the tested compounds, were analysed by a computer fitting procedure (GraphPad Prism 5.0) and expressed as mean \pm S.E.M. with at least five different curves performed for each compound. Behavioural measurements were performed on 16 mice for each treatment carried out in two different experimental sets. Investigators were blind to all experimental procedures. Results were expressed as mean \pm S.E.M. The analysis of variance of data was performed by one-way analysis of variance, and a Bonferroni's significant difference procedure was used as post hoc comparison. $p$ values of less than $0.05,0.01$, or 0.001 were considered significant. Data were analysed using the "Origin 9" software (OriginLab, Northampton).

\section{3 | RESULTS}

As already observed for other natural ITCs (Citi et al., 2014), SFN exhibited significant L-cysteine-dependent release of $\mathrm{H}_{2} \mathrm{~S}$. In particular, the incubation of SFN $1 \mathrm{mM}$ led to a slow formation of $\mathrm{H}_{2} \mathrm{~S}$, reaching a steady-state concentration of about $0.75 \mu \mathrm{M}$; in the absence of L-cysteine, the $\mathrm{H}_{2} \mathrm{~S}$ generation from SFN was almost completely negligible. Only in the presence of this amino acid, the incubation of SFN with L-cysteine led to the formation of $\mathrm{H}_{2} \mathrm{~S}$ (Figure 1a). Surprisingly, the glucosinolate GRA showed a similar behaviour: in the presence of L-cysteine, the incubation of GRA $1 \mathrm{mM}$ led to a slow formation of $\mathrm{H}_{2} \mathrm{~S}$, reaching a steady-state concentration of about $1 \mu \mathrm{M}$ (Figure $1 \mathrm{~b}$ ), whereas in the absence of L-cysteine, the $\mathrm{H}_{2} \mathrm{~S}$ generation from both SFN and GRA was almost completely negligible (Figure $1 \mathrm{a}$ and $1 \mathrm{~b}$ ).

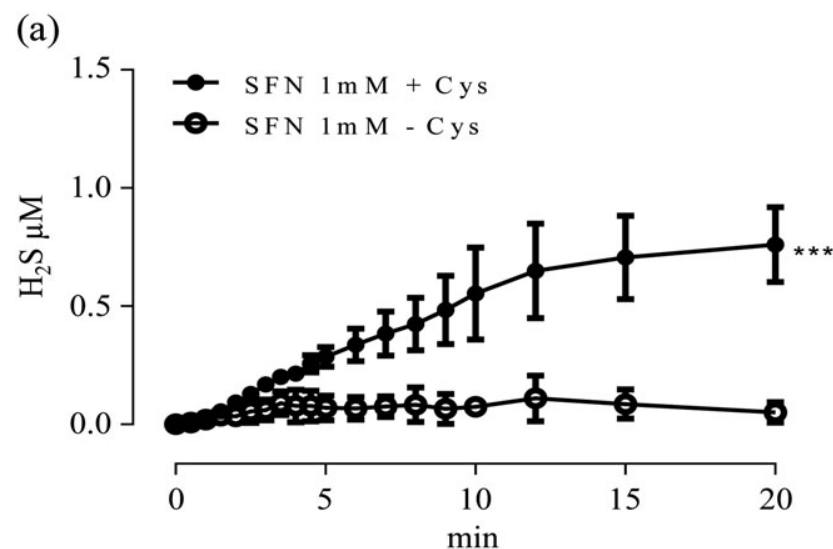

(b)

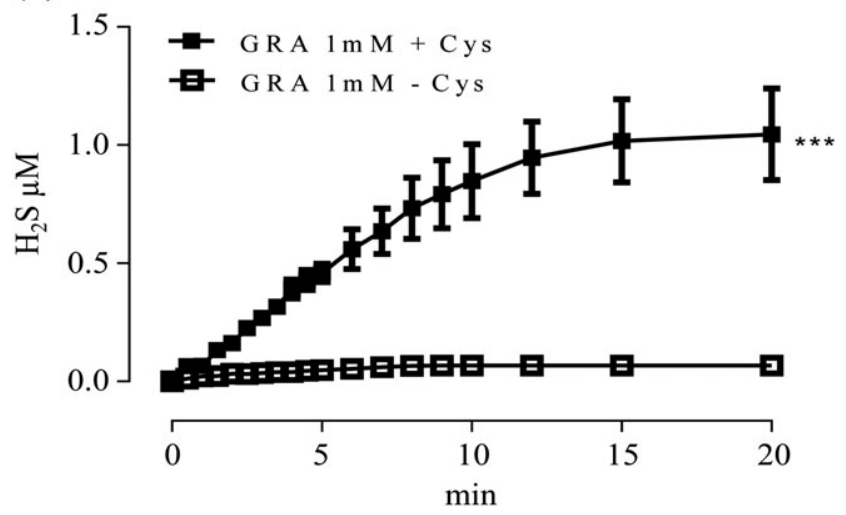

FIGURE 1 Hydrogen sulfide release from sulforaphane (SFN) and glucoraphanin (GRA). The curves describe the increase of the $\mathrm{H}_{2} \mathrm{~S}$ concentration with respect to time, following the incubation of SFN (a) and GRA (b) $1 \mathrm{mM}$, in the absence (-Cys) and in the presence (+Cys) of L-cysteine $4 \mathrm{mM}$. $\mathrm{H}_{2} \mathrm{~S}$ was recorded by amperometric approach. The vertical bars indicate S.E.M. and the ${ }^{* * *}$ a $p<0.001$

Figure 2 shows the effect of acute subcutaneous and oral administrations of different doses of GRA $(4.43,13.31,39.93$, and $119.79 \mu \mathrm{mol} \mathrm{kg}-1)$ and SFN (1.33, 4.43, and $13.31 \mu \mathrm{mol} \mathrm{kg}-1)$ in oxaliplatin-treated mice (Figure 2a-d, respectively). On Day 15, oxaliplatin-treated mice showed a significantly decreased latency to pain-related behaviours induced by the cold stimulus ( $11.5 \pm 0.9 \mathrm{~s}$ ) compared with control mice treated with vehicle $(21.4 \pm 1.7 \mathrm{~s}$; Figure 2$)$. By both oral and subcutaneous administration, GRA effectively relieved pain in mice, increasing the licking latency in a dose-dependent manner GRA resulted active starting from $13.31 \mu \mathrm{mol} \mathrm{kg}{ }^{-1}$. The higher doses (39.93 and $119.79 \mu \mathrm{mol} \mathrm{kg}{ }^{-1}$ ) of GRA effectively reduced neuropathic pain in the animals starting 15 min after administration and the effect lasted until $45 \mathrm{~min}$ (Figure $2 \mathrm{a}$ and $2 \mathrm{~b}$ ). Orally administered $119.79 \mu \mathrm{mol} \mathrm{kg}{ }^{-1}$ of GRA were able to revert the pain threshold of animals back to the value of controls already 15 min after administration (Figure 2a). SFN resulted active starting from $4.33 \mu \mathrm{mol} \mathrm{kg}{ }^{-1}$ by both the routes of administration, with a peak of effect $30 \mathrm{~min}$ after the injection. The highest tested dose of SFN (13.31 $\left.\mu \mathrm{mol} \mathrm{kg}^{-1}\right)$ completely relieved neuropathic pain in the animals (Figure $2 \mathrm{c}$ and $2 \mathrm{~d}$ ).

The effect of the subcutaneous and orally repeated treatment with GRA and SFN on chemotherapy-induced neuropathic pain in mice is shown in Figure $3 a$ and $3 b$, respectively. Repeated treatment consisted of a daily administration following the same protocol 
(a)
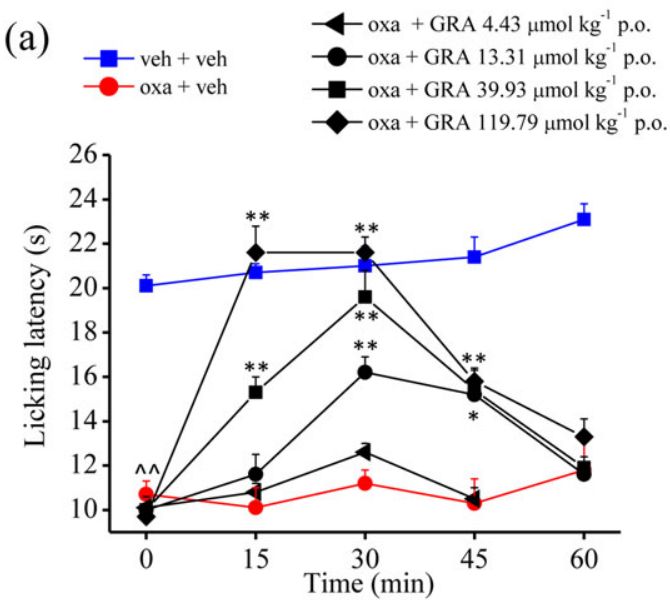

(c)
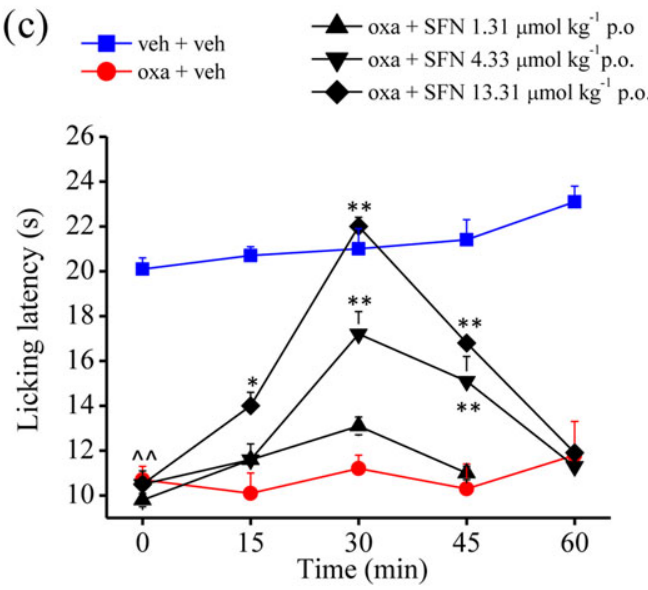

(b)
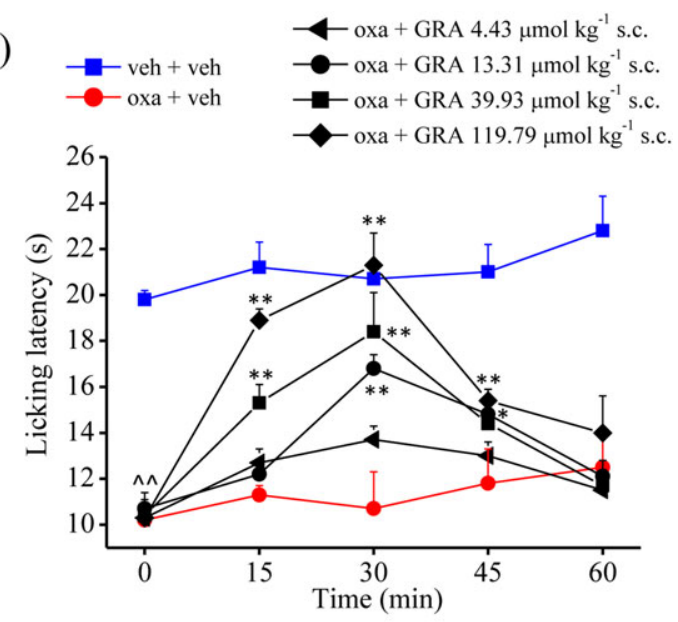

(d)
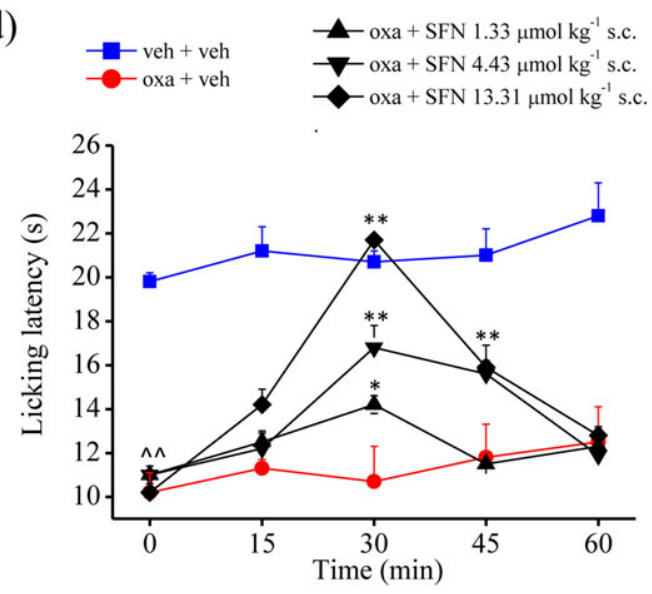

FIGURE 2 Effect of glucoraphanin (GRA) and sulforaphane (SFN) acute administration on chemotherapy-induced neuropathic pain. The response to a thermal stimulus was evaluated by the cold plate test measuring the latency(s) to pain-related behaviours (lifting or licking of the paw). Mice were intraperitoneally treated with oxaliplatin $2.4 \mathrm{mg} \mathrm{kg}^{-1}$ to induce neuropathic pain. Behavioural tests were performed on Day 15 . GRA $\left(4.43,13.31,39.93\right.$, and $\left.119.79 \mu \mathrm{mol} \mathrm{kg}^{-1}\right)$ and SFN $\left(1.33,4.43\right.$, and $\left.13.31 \mu \mathrm{mol} \mathrm{kg}{ }^{-1}\right)$ were dissolved in $1 \%$ carboxymethyl cellulose and saline solution, respectively, for oral and subcutaneous administration (a, b, c, and d, respectively). Measurements were performed 15, 30, 45, and 60 min after injection. ${ }^{\wedge \wedge} p<0.01$ versus vehicle + vehicle-treated mice; ${ }^{*} p<0.05$ and ${ }^{* *} p<0.01$ versus oxaliplatin + vehicle-treated mice [Colour figure can be viewed at wileyonlinelibrary.com]

described for oxaliplatin from the first up to the $14^{\text {th }}$ day. Behavioural tests were performed on Days 8 and 15, 24 hours after the treatment. The enhancement of pain threshold induced by the repeated oral and subcutaneous treatment with GRA (13.31 $\mu \mathrm{mol} \mathrm{\textrm {kg } ^ { - 1 }}$ ) and SFN $\left(4.43 \mu \mathrm{mol} \mathrm{kg}^{-1}\right)$ is shown in comparison with oxaliplatin-treated mice. Pain threshold of animals treated with oxaliplatin resulted progressively decreased in comparison with control mice starting from Day 8 until Day 15, when the neuropathy resulted established (Figure 3a and $3 b$ ). The licking latency of the animals treated with oxaliplatin and GRA, oral and subcutaneous administered, resulted significantly higher in comparison with oxaliplatin-treated mice both on Days 8 and 15 (Figure 3a). As result of orally repeated treatment with SFN, the animals showed a pain threshold significantly increased in comparison with oxaliplatin-treated mice both on Days 8 and 15 (Figure 3b). On the other hand, the subcutaneous treatment with SFN resulted significant only on Day 15 (Figure 3b).

To evaluate the role of $\mathrm{H}_{2} \mathrm{~S}$ release in their antihyperalgesic effect, GRA and SFN were subcutaneously administered in mixture with $\mathrm{Hb}$, a molecule able to bind $\mathrm{H}_{2} \mathrm{~S}$ (Mishanina, Libiad, \& Banerjee, 2015) and so to prevent its pharmacological activities. Both Figure 3a and $3 \mathrm{~b}$ show the acute antihyperalgesic effect induced by GRA $\left(13.31 \mu \mathrm{mol} \mathrm{kg}^{-1} \mathrm{sc}\right)$ and SFN $\left(4.43 \mu \mathrm{mol} \mathrm{kg}{ }^{-1} \mathrm{sc}\right)$ in oxaliplatin-treated animals. The co-administration with $\mathrm{Hb}\left(3.1 \mu \mathrm{mol} \mathrm{kg}{ }^{-1} \mathrm{sc}\right)$ was able to fully prevent the antineuropathic efficacy of both GRA and SFN. In fact, the pain threshold of animals treated with GRA and SFN in mixture with $\mathrm{Hb}$ was not significantly different from that of oxaliplatin + vehicle-treated animals (Figure $4 a$ and $4 b$ ). The suppression of the pain-relieving efficacy of GRA and SFN mediated by $\mathrm{Hb}$ can be further appreciated considering the resulting AUC (Figure 4b).

To demonstrate the involvement of Kv7 potassium channel in the antineuropathic effect of GRA and SFN, a selective Kv7 blocker, XE991, was administered 15 min before these phytochemicals. In Figure $5 \mathrm{a}$ and $5 \mathrm{~b}$ was shown the effect induced by the single administration of GRA (13.31 $\mathrm{mmol} \mathrm{kg}^{-1}$ po) and SFN (4.43 $\mu \mathrm{mol} \mathrm{kg^{-1 }}$ po) in oxaliplatin-treated animals in comparison with that displayed after the pretreatment with XE991 $\left(7.98 \mu \mathrm{mol} \mathrm{kg}{ }^{-1}\right.$ ip). The pain relieving activity of GRA and SFN was fully prevented by the intraperitoneal administration of XE991, as evidenced by both Figure $5 a$ and $5 b$, showing the licking latency and the resulting AUC, respectively. 


\section{(a)}
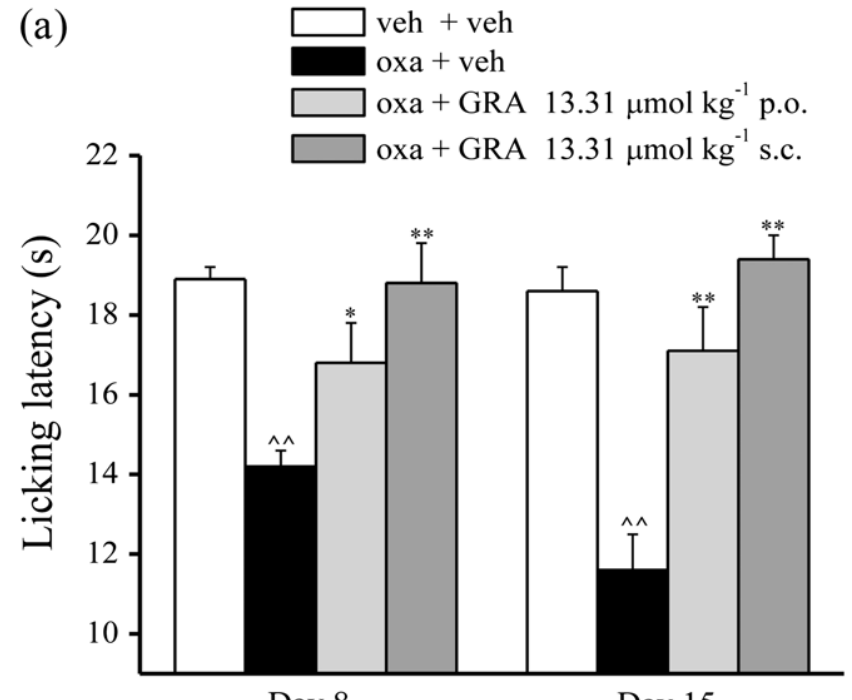

Day 8

Day 15

(b)
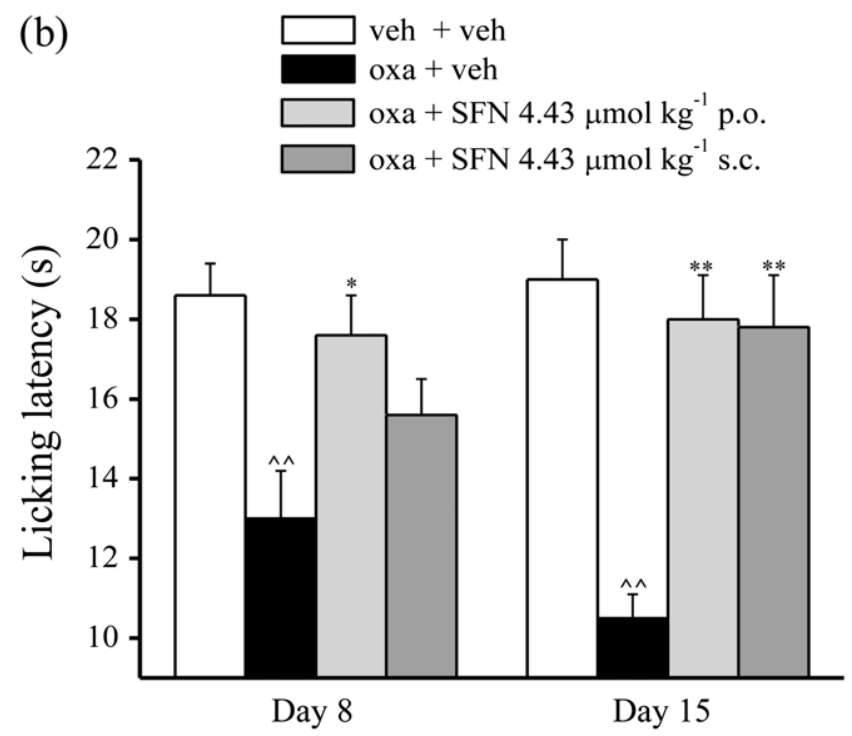

FIGURE 3 Effect of the repeated treatment with glucoraphanin (GRA) and sulforaphane (SFN) on chemotherapy-induced neuropathic pain. Mice were intraperitoneally treated with oxaliplatin $2.4 \mathrm{mg} \mathrm{kg}^{-1}$ to induce neuropathic pain. The response to a thermal stimulus was evaluated by the cold plate test measuring the latency(s) to pain-related behaviours (lifting or licking of the paw). GRA (13.31 $\mu \mathrm{mol} \mathrm{kg}^{-1}$; a) and SFN ( $4.43 \mu \mathrm{mol} \mathrm{kg}^{-1}$; b) were dissolved in $1 \%$ carboxymethyl cellulose and saline solution, respectively, for oral and subcutaneous administration. Repeated treatment consisted of a daily administration following the same protocol described for oxaliplatin from the first up to the $14^{\text {th }}$ day. Behavioural tests were performed on Days 8 and 15, $24 \mathrm{hr}$ after the treatment. $\wedge^{\wedge} p<0.01$ versus vehicle + vehicle treated mice; ${ }^{*} p<0.05$ and ${ }^{* *} p<0.01$ versus oxaliplatin + vehicle-treated mice

\section{4 | DISCUSSION}

The development of neuropathic pain is a severe dose-limiting side effect of commonly used chemotherapeutic agents (Ward et al., 2014). Antidepressants and antiepileptics, currently considered the elective therapy for these types of pain, show a low efficacy and several negative side effects (Cruccu \& Truini, 2017). It is thus clear that, for the management of this type of pain, innovative, safe, and effective treatments still have to be developed.

Recently, it has been observed that synthetic and natural ITC compounds are efficient in relieving neuropathic pain induced in animals by chemotherapic agents, as paclitaxel and oxaliplatin (Di Cesare Mannelli et al., 2017). In line with the previous data, the present results show that the natural enantiopure isothiocyanate $R$-SFN and its precursor GRA effectively reduce the hypersensitivity to a cold non-noxious stimulus (allodynia-related measurement) after acute administration in oxaliplatin-treated animals.

GRA resulted slightly less effective by subcutaneous administration than by oral administration, suggesting that the gastroenteric metabolism enhances the bioavailability of the active compound (Fahey et al., 2015).

This evidence is in line with the fact that GRA frequently is bioactivated with MYR before the administration in vivo and in vitro (Galuppo et al., 2013), suggesting that the responsible for most of the pharmacological properties showed by these phytochemicals is actually SFN. This point was strengthened by the present findings, because SFN resulted 10 fold more potent than GRA.

In addition to the acute effect on neuropathic pain, both GRA and SFN, when repeatedly administered in the animals starting from the first day of oxaliplatin treatment, resulted able to reduce the development of neuropathy. Besides, both GRA and SFN showed beneficial neuroprotective effects in different conditions of central and peripheral nervous system damage (Giacoppo et al., 2014). Particularly, the treatment with the glucosinolate seems able to shot down the astrocytes activation in the spinal cord, condition that results strongly associated with the establishment and the persistence of neuropathic pain (Di Cesare Mannelli et al., 2014; Galuppo et al., 2013).

In the years, many mechanisms of action were attributed to SFN. Among them, the most studied were the antioxidant and anti-inflammatory effects (Guerrero-Beltrána et al., 2012; Heiss et al., 2001). Indeed SFN has been described as a strong enhancer of Nrf2-ARE pathway (Negi et al., 2011) and a suppressor of NF-kB signalling pathway (Heiss et al., 2001).

However, although the antioxidative properties could explain the neuroprotective effect showed by the repeated treatments both with SFN and GRA (Areti, Yerra, Naidu, \& Kumar, 2014), it is unlikely this mechanism could be responsible for the acute antihyperalgesic effect showed by these molecules. In this regard, our results are consistent with the previous findings demonstrating that synthetic and natural ITCs act as $\mathrm{H}_{2} \mathrm{~S}$-releasing compounds (Citi et al., 2014; Di Cesare Mannelli et al., 2017). In fact, the amperometric recordings showed that actually SFN shows a $\mathrm{H}_{2} \mathrm{~S}$-donor profile. Surprisingly, even GRA showed an almost equivalent behaviour of $\mathrm{H}_{2} \mathrm{~S}$-releasing agent. The role of $\mathrm{H}_{2} \mathrm{~S}$ in the analgesic effects of both SFN and GRA seems to be strongly supported by the observation that the $\mathrm{H}_{2} \mathrm{~S}$-binding molecule $\mathrm{Hb}$ (Mishanina et al., 2015) fully prevented the antihyperalgesic efficacy of both GRA and SFN. It is thus possible that many other health benefits of cruciferous vegetables involve $\mathrm{H}_{2} \mathrm{~S}$. Indeed SFN is probably implicated in the regulation of $\mathrm{H}_{2} \mathrm{~S}$ levels in vivo, as this gasotransmitter is an important factor in the anticancer activity (Liu, Wu, Montaut, \& Yang, 2016), as well as in the cardiovascular beneficial effect exerted by SFN (Martelli et al., 2014). 


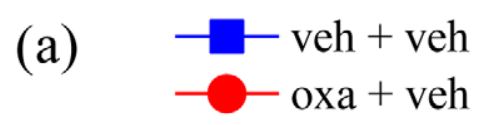

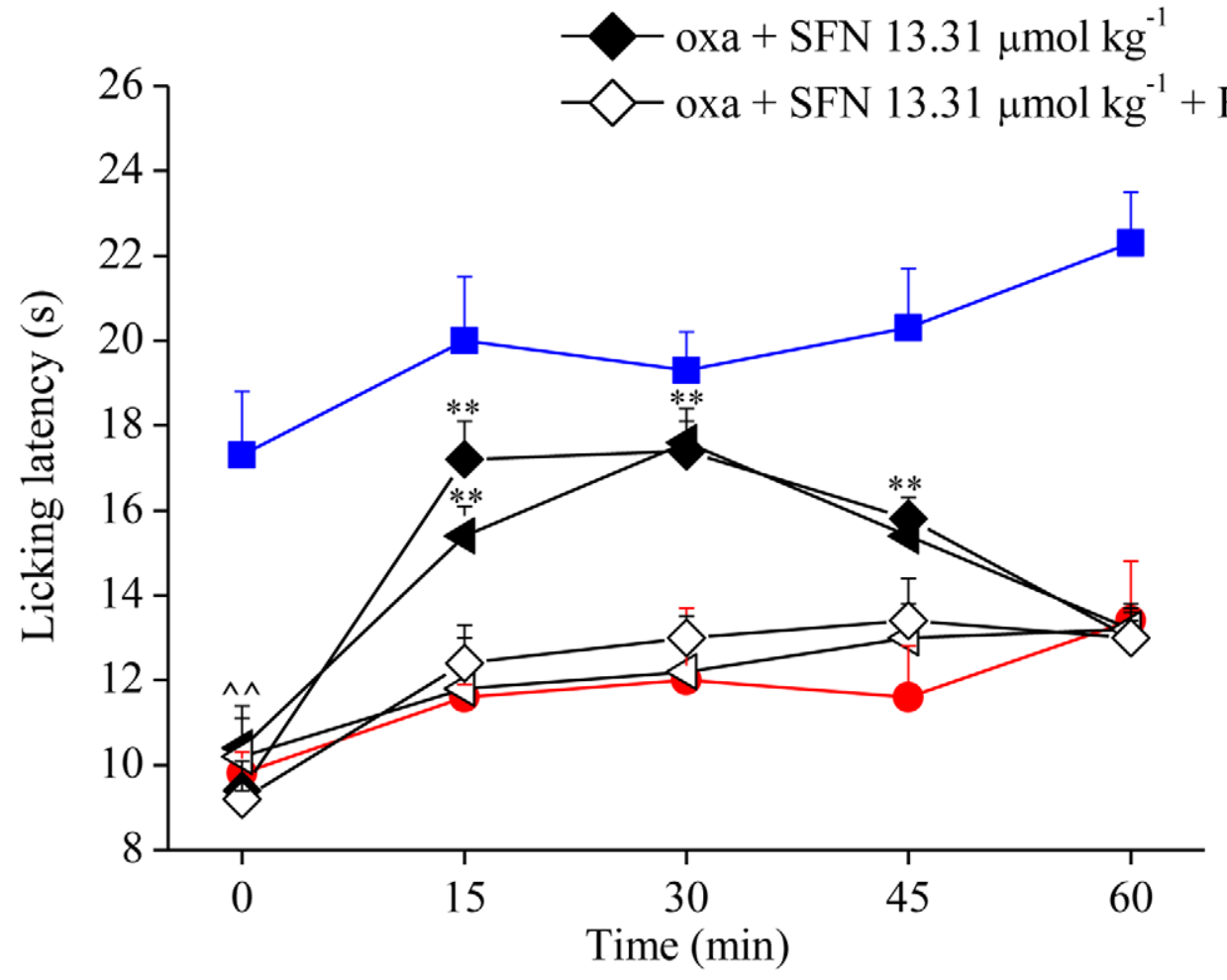

(b)
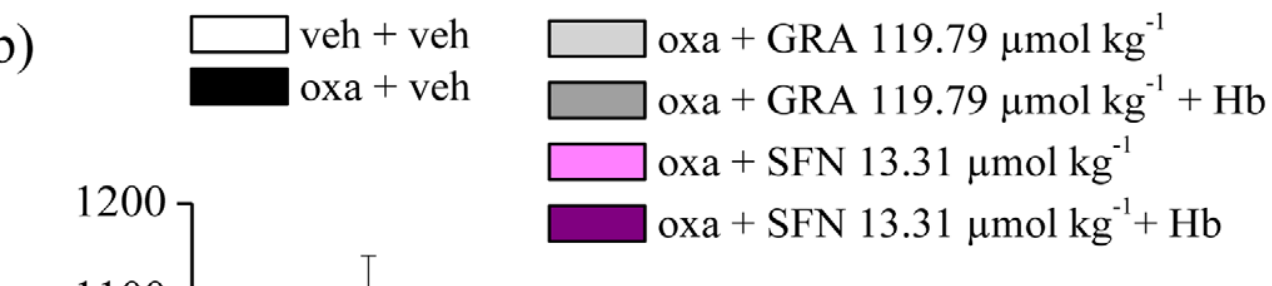

$$
\begin{aligned}
& \text { oxa + GRA } 119.79 \mu \mathrm{mol} \mathrm{kg}^{-1} \\
& \text { oxa + GRA } 119.79 \mu \mathrm{mol} \mathrm{kg}^{-1}+\mathrm{Hb} \\
& \text { oxa + SFN } 13.31 \mu \mathrm{mol} \mathrm{kg}
\end{aligned}
$$

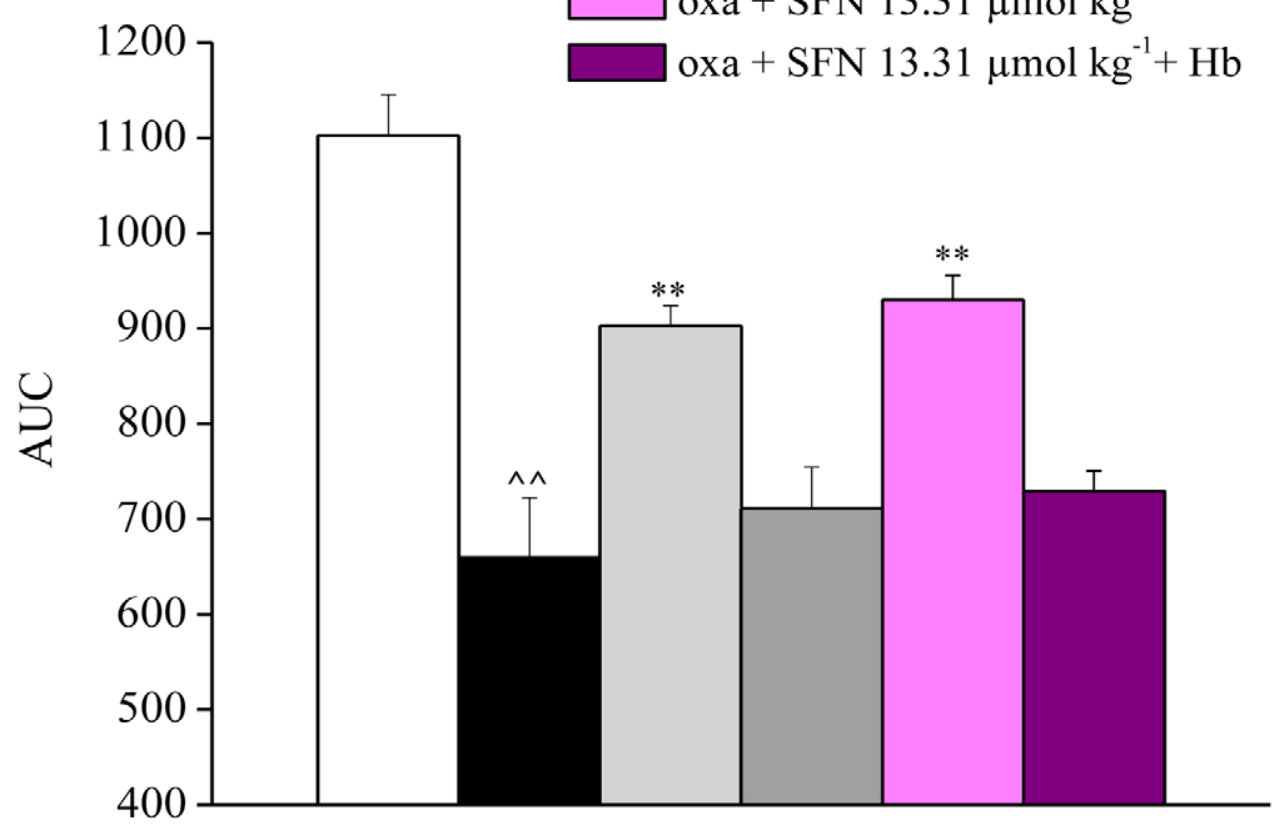

oxa + SFN $13.31 \mu \mathrm{mol} \mathrm{kg}{ }^{-1}+\mathrm{Hb}$

FIGURE 4 Role of $\mathrm{H}_{2} \mathrm{~S}$ in the relief of oxaliplatin-induced neuropathic pain of glucoraphanin (GRA) and sulforaphane (SFN). The latency(s) to pain-related behaviours (lifting or licking of the paw) was measured by the cold plate test, measuring the latency(s) to pain-related behaviours (lifting or licking of the paw). Mice were intraperitoneally treated with oxaliplatin ( $\left.2.4 \mathrm{mg} \mathrm{kg}^{-1}\right)$, and behaviour was measured on Day 15 . GRA $\left(119.79 \mu \mathrm{mol} \mathrm{kg}^{-1}\right)$ and SFN $\left(13.31 \mu \mathrm{mol} \mathrm{kg}{ }^{-1}\right)$ were subcutaneously administered alone or in mixture with $\mathrm{Hb}\left(3.10 \mu \mathrm{mol} \mathrm{kg}{ }^{-1}\right) . \mathrm{Measurements}$ were performed 15, 30, 45, and 60 min after injection (a). The histogram shows the average of resulting AUC (b). Control mice were treated with vehicle. Each value represents the mean of 16 mice per group, performed in two different experimental sets. ${ }^{\wedge} p<0.01$ versus vehicle + vehicletreated mice; ${ }^{*} p<0.05$ and ${ }^{* *} p<0.01$ versus oxaliplatin + vehicle-treated mice [Colour figure can be viewed at wileyonlinelibrary.com] 
(a)

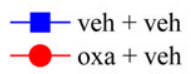

- oxa + GRA $119.79 \mu \mathrm{mol} \mathrm{kg}^{-1}$

$\checkmark$ oxa + GRA $119.79 \mu \mathrm{mol} \mathrm{kg}^{-1}+$ XE991

oxa + SFN $13.31 \mu \mathrm{mol} \mathrm{kg}^{-1}$

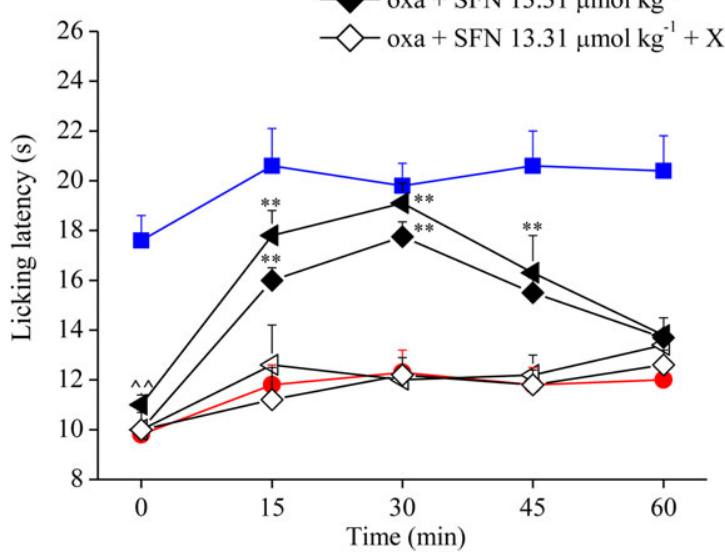

(b)

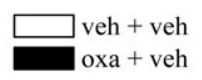

$\square$ oxa + GRA $119.79 \mu \mathrm{mol} \mathrm{kg}^{-1}$

$\square$ oxa + GRA $119.79 \mu \mathrm{mol} \mathrm{kg}{ }^{-1}+$ XE991

$\square$ oxa + SFN $13.31 \mu \mathrm{mol} \mathrm{kg}^{-1}$

$\square$ oxa + SFN $13.31 \mu \mathrm{mol} \mathrm{kg}^{-1}+$ XE991

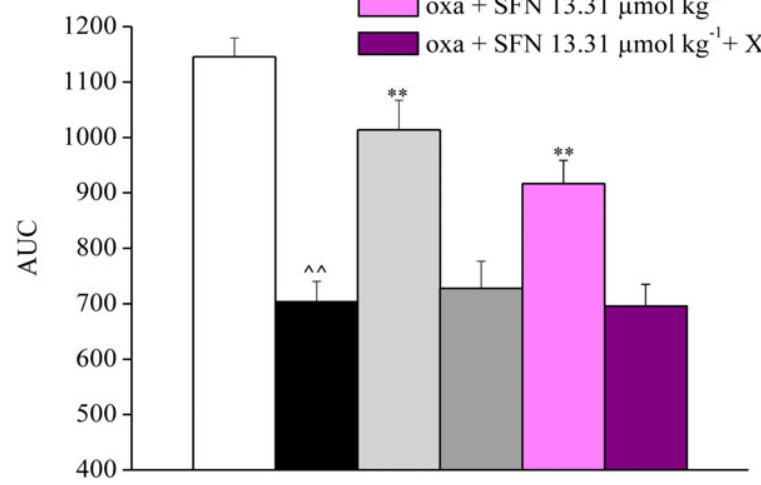

FIGURE 5 Involvement of $\mathrm{Kv7}$ potassium channels in $\mathrm{H}_{2} \mathrm{~S}$-mediated antineuropathic effect of glucoraphanin (GRA) and sulforaphane (SFN). The latency(s) to pain-related behaviours (lifting or licking of the paw) was measured by the cold plate test, measuring the latency(s) to pain-related behaviours (lifting or licking of the paw). Mice were intraperitoneally treated with oxaliplatin $\left(2.4 \mathrm{mg} \mathrm{kg}^{-1}\right)$ and behaviour was measured on Day 15. GRA (119.79 $\left.\mu \mathrm{mol} \mathrm{kg}^{-1}\right)$ and SFN (13.31 $\left.\mu \mathrm{mol} \mathrm{kg}{ }^{-1}\right)$ were administered oral. XE991 $\left(7.98 \mu \mathrm{mol} \mathrm{kg}^{-1}\right)$ was intraperitoneally administered $15 \mathrm{~min}$ before GRA and SFN. Measurements were performed $15,30,45$, and 60 min after injection (a). The histograms show the average of resulting AUC (b). Control mice were treated with vehicle. Each value represents the mean of 16 mice per group, performed in two different experimental sets. ${ }^{\wedge} p p<0.01$ versus vehicle + vehicletreated mice; ${ }^{*} p<0.05$ and ${ }^{* *} p<0.01$ versus oxaliplatin + vehicletreated mice [Colour figure can be viewed at wileyonlinelibrary.com]

Noteworthy, the effects displayed by this gasotransmitter showed a bell-shaped dose-dependence both in vivo and in vitro (Di Cesare Mannelli et al., 2017). It is thus deductible that the kinetic of $\mathrm{H}_{2} \mathrm{~S}$ release from $\mathrm{H}_{2} \mathrm{~S}$ donor compounds is a paramount factor for their pharmacological properties. Regarding this, the $\mathrm{H}_{2} \mathrm{~S}$ slow-releasing capacity was demonstrated to be an important feature for $\mathrm{H}_{2} \mathrm{~S}$ donors (Citi et al., 2014). In fact, in vitro, low concentrations of $\mathrm{H}_{2} \mathrm{~S}$ donors resulted beneficial, whereas the elevation of $\mathrm{H}_{2} \mathrm{~S}$ concentrations beyond a certain concentration range can become cytotoxic, prooxidant, and suppresses mitochondrial electron transport (Szabo et al., 2014). Similarly, in vivo, $\mathrm{H}_{2} \mathrm{~S}$ is effective in relieving neuropathic pain at very low doses, but by increasing the dose, the effect decreases (Di Cesare Mannelli et al., 2017).

A further proof is the fact that slow $\mathrm{H}_{2} \mathrm{~S}$ donors, such as GYY4137, are often more effective than rapid donors, such as NaHS, suggesting that long-lasting generation of relatively lower concentrations of $\mathrm{H}_{2} \mathrm{~S}$ can be preferable ( $\mathrm{Li}$ et al., 2008), as this gas is able to easily reach the blood stream and then its molecular targets on the cell membrane, inside the cytosol or in intracellular organelles (Wallace \& Wang, 2015). In the past, some series of different $\mathrm{H}_{2} \mathrm{~S}$ pro-drugs were developed (Zheng, Ji, Ji, \& Wang, 2015) often obtaining a limited control of gas release. In this context, GRA, being hydrolysable in vivo (Fahey et al., 2015), could be usefully employed for therapeutic purposes. In fact, even though SFN seems to be the responsible for the antihyperalgesic effect showed by GRA, the latter showed a better kinetic profile after the administration in the animals, with a more prolonged effect. Therefore, considering that GRA is more stable than SFN especially in solution (Fahey et al., 2017) and that GRA could mediate a slow release of SFN and consequently of $\mathrm{H}_{2} \mathrm{~S}$ in vivo, it could be more advantageous to use the intact glucosinolate instead of the ITC, even though the latter results more potent.

Looking further into the mechanisms of action with which the ITCs can influence pain perception, it is noteworthy that the activation of Kv7 potassium channels may have a relevant role, among the pleiotropic mechanisms of action played by $\mathrm{H}_{2} \mathrm{~S}$ in different biological systems (Martelli et al., 2013). Consistently, we found that GRA and SFN, as other ITC-based compounds, can modulate the activity of the voltage-gated Kv7 potassium channels (Di Cesare Mannelli et al., 2017). This type of potassium channels plays a pivotal role in pain modulation (Nodera, Spieker, Sung, \& Rutkove, 2011). In fact, Kv7 channels activators, as retigabine and flupirtine show antihyperalgesic effects that were mainly related to the suppression of sensitive neurons excitability (Sittl, Carr, Fleckenstein, \& Grafe, 2010). Given that the abnormal painful signalling during neuropathic condition is due to an overexpression and overactivation of ion channels and receptors in neurons, probably, the $\mathrm{H}_{2} \mathrm{~S}$ released from GRA and SFN could act on neuropathic pain by activating Kv7 channels along pain pathways. This initial consideration was confirmed by the present data showing that the pain-relieving effect of both GRA and SFN is abolished by pretreating the animals with the Kv7 channel blocker, XE991.

In conclusion, the present study demonstrates that natural GRA and the enantiopure $R$-SFN effectively reduce neuropathic pain induced by chemotherapy through the release of $\mathrm{H}_{2} \mathrm{~S}$ in vivo and the activation of $\mathrm{Kv} 7$ channels. The effectiveness of SFN as well as that of other natural-occurring ITC (allyl isothiocyanate; Di Cesare Mannelli et al., 2017), mainly obtained from Brassicaceae, introduces the possibility to exploit this family of plants for an innovative approach to drug-resistant forms of pain such as chemotherapyinduced neuropathy. Indeed, the obtained results provide a new mechanism of action for these type of phytochemicals, which, adding to their well-known neuroprotective properties, strengthen the rational of their use in the management of neuropathic pain: on one side, the repetitive administration of these compounds could be aimed to prevent the development of neurological disease during the 
chemotherapic treatment. On the other side, these compounds could be acutely used to give an immediate pain relief.

Finally, it is also important to consider that these compounds are largely present in many common edible plant belonging to Brassiceae family, rising the interesting possibility to use foods and supplements enriched with glucoraphanin and sulforaphane to support and enhance pain therapies. It might also allow an easier and safer translation to clinical application. To this end, the $\mathrm{H}_{2} \mathrm{~S}$-release kinetic of these compounds could be further investigated in order to improve their pharmacokinetic profile and, therefore, to maximizing their pharmacological effects.

\section{ACKNOWLEDGEMENTS}

This research was funded by the Italian Ministry of Instruction, University and Research (MIUR) and by the Universities of Florence and Pisa.

\section{CONFLICT OF INTEREST}

The authors declare that there are no known conflicts of interest associated with this publication and there has been no significant financial support for this work that could have influenced its outcome.

\section{ORCID}

Lara Testai (iD) http://orcid.org/0000-0003-2431-6248

Lorenzo Di Cesare Mannelli (D) http://orcid.org/0000-0001-8374-4432

\section{REFERENCES}

Areti, A., Yerra, V. G., Naidu, V., \& Kumar, A. (2014). Oxidative stress and nerve damage: Role in chemotherapy induced peripheral neuropathy. Redox Biology, 2, 289-295.

Blackburn-Munro, G., \& Jensen, B. S. (2003). The anticonvulsant retigabine attenuates nociceptive behaviours in rat models of persistent and neuropathic pain. European Journal of Pharmacology, 460(2-3), 109-116.

Cavaletti, G., Tredici, G., Petruccioli, M. G., Donde, E., Tredici, P., Marmiroli, P., ... Griffon Etienne, G. (2001). Effects of different schedules of oxaliplatin treatment on the peripheral nervous system of the rat. European Journal of Cancer, 37(18), 2457-2463.

Citi, V., Martelli, A., Testai, L., Marino, A., Breschi, M. C., \& Calderone, V. (2014). Hydrogen sulfide releasing capacity of natural isothiocyanates: Is it a reliable explanation for the multiple biological effects of Brassicaceae? Planta Medica, 80, 610-613.

Cruccu, G., \& Truini, A. (2017). A review of neuropathic pain: From guidelines to clinical practice. Pain and Therapy, 6(1), 35-42.

De Nicola, G. R., Rollin, P., Mazzon, E., \& lori, R. (2014). Novel gram-scale production of enantiopure R-sulforaphane from Tuscan black kale seeds. Molecules, 19(6), 6975-6986.

Di Cesare Mannelli, L., Lucarini, E., Micheli, L., Mosca, I., Ambrosino, P., Soldovieri, M. V., ... Ghelardini, C. (2017). Effects of natural and synthetic isothiocyanate-based $\mathrm{H}_{2} \mathrm{~S}$-releasers against chemotherapyinduced neuropathic pain: Role of Kv7 potassium channels. Neuropharmacology, 121, 49-59.

Di Cesare Mannelli, L., Maresca, M., Farina, C., Scherz, M. W., \& Ghelardini, C. (2015). A model of neuropathic pain induced by sorafenib in the rat: Effect of dimiracetam. Neurotoxicology, 50, 101-107.

Di Cesare Mannelli, L., Pacini, A., Micheli, L., Tani, A., Zanardelli, M., \& Ghelardini, C. (2014). Glial role in oxaliplatin-induced neuropathic pain. Experimental Neurology, 261, 22-33.
Dinkova-Kostova, A. T., \& Kostov, R. V. (2012). Glucosinolates and isothiocyanates in health and disease. Trends in Molecular Medicine, 18(6), 337-347.

Fahey, J. W., Holtzclaw, W. D., Wehage, S. L., Wade, K. L., Stephenson, K. K., \& Talalay, P. (2015). Sulforaphane bioavailability from glucoraphanin-rich broccoli: Control by active endogenous myrosinase. PLoS One, 10(11), e0140963.

Fahey, J. W., Wade, K. L., Wehage, S. L., Holtzclaw, W. D., Liu, H., Talalay, P., ... Stephenson, K. K. (2017). Stabilized sulforaphane for clinical use: Phytochemical delivery efficiency. Molecular Nutrition \& Food Research, 61(4).

Galuppo, M., Giacoppo, S., De Nicola, G. R., lori, R., Mazzon, E., \& Bramanti, P. (2013). Rs-Glucoraphanin bioactivated with myrosinase treatment counteracts proinflammatory cascade and apoptosis associated to spinal cord injury in an experimental mouse model. Journal of the Neurological Sciences, 334(1-2), 88-96.

Giacoppo, S., Galuppo, M., Iori, R., De Nicola, G. R., Bramanti, P., \& Mazzon, E. (2014). ( $\left(R_{S}\right)$-glucoraphanin purified from Tuscan black kale and bioactivated with myrosinase enzyme protects against cerebral ischemia/reperfusion injury in rats. Fitoterapia, 99, 166-177.

Guerrero-Beltrána, C. E., Calderón-Oliver, M., Pedraza-Chaverri, J., \& Chirino, Y. I. (2012). Protective effect of sulforaphane against oxidative stress: Recent advances. Experimental and Toxicologic Pathology, 64(5), 503-508.

Heiss, E., Herhaus, C., Klimo, K., \& Bartsch, H. (2001). Nuclear factor кB is a molecular target for sulforaphane-mediated anti-inflammatory mechanisms. The Journal of Biological Chemistry, 276(34), 32008-32015.

Li, L., Whiteman, M., Guan, Y. Y., Neo, K. L., Cheng, Y., Lee, S. W., ... Moore, P. K. (2008). Characterization of a novel, water-soluble hydrogen sulfide-releasing molecule (GYY4137): New insights into the biology of hydrogen sulfide. Circulation, 117, 2351-2360.

Liu, M., Wu, L., Montaut, S., \& Yang, G. (2016). Hydrogen sulfide signaling axis as a target for prostate cancer therapeutics. Prostate Cancer, 2016, 1, 8108549-9.

Martelli, A., Testai, L., Breschi, M. C., Lawson, K., McKay, N. G., Miceli, F., ... Calderone, V. (2013). Vasorelaxation by hydrogen sulphide involves activation of Kv7 potassium channels. Pharmacological Research, 70(1), 27-34.

Martelli, A., Testai, L., Citi, V., Marino, A., Bellagambi, F. G., Ghimenti, S., ... Calderone, V. (2014). Pharmacological characterization of the vascular effects of aryl isothiocyanates: Is hydrogen sulfide the real player? Vascular Pharmacology, 60(1), 32-41.

McGrath, J. C., \& Lilley, E. (2015). Implementing guidelines on reporting research using animals (ARRIVE etc.): New requirements for publication in BJP. British Journal of Pharmacology, 172(13), 3189-3193.

Mishanina, T. V., Libiad, M., \& Banerjee, R. (2015). Biogenesis of reactive sulfur species for signaling by hydrogen sulfide oxidation pathways. Nature Chemical Biology, 11(7), 457-464.

Negi, G., Kumar, A., \& Sharma, S. S. (2011). Nrf2 and NF-кB modulation by sulforaphane counteracts multiple manifestations of diabetic neuropathy in rats and high glucose-induced changes. Current Neurovascular Research, 8(4), 294-304.

Nodera, H., Spieker, A., Sung, M., \& Rutkove, S. (2011). Neuroprotective effects of Kv7 channel agonist, retigabine, for cisplatin-induced peripheral neuropathy. Neuroscience Letters, 505(3), 223-227.

Sittl, R., Carr, R. W., Fleckenstein, J., \& Grafe, P. (2010). Enhancement of axonal potassium conductance reduces nerve hyperexcitability in an in vitro model of oxaliplatin-induced acute neuropathy. Neurotoxicology, 31, 694-700.

Szabo, C., Ransy, C., Módis, K., Andriamihaja, M., Murghes, B., Coletta, C., ... Bouillaud, F. (2014). Regulation of mitochondrial bioenergetic function by hydrogen sulfide. Part I. Biochemical and physiological mechanisms. British Journal of Pharmacology, 171, 2099-2122.

Wallace, J. L., \& Wang, R. (2015). Hydrogen sulfide-based therapeutics: Exploiting a unique but ubiquitous gasotransmitter. Nature Reviews Drug Discovery, 14(5), 329-345. 
Wang, X., De Rivero Vaccari, J. P., Wang, H., Diaz, P., German, R., Marcillo, A. E., \& Keane, R. W. (2012). Activation of the nuclear factor E2-related factor 2/antioxidant response element pathway is neuroprotective after spinal cord injury. Journal of Neurotrauma, 29, 936-945.

Ward, S. J., McAllister, S. D., Kawamura, R., Murase, R., Neelakantan, H., \& Walker, E. A. (2014). Cannabidiol inhibits paclitaxel-induced neuropathic pain through 5-HT1A receptors without diminishing nervous system function or chemotherapy efficacy. British Journal of Pharmacology, 171, 636-645.

Xu, C., Huang, M. T., Shen, G., Yuan, X., Lin, W., Khor, T. O., ... Kong, A. N. (2006). Inhibition of 7, 12-dimethylbenz (a) anthracene-induced skin tumorigenesis in C57BL/6 mice by sulforaphane is mediated by nuclear factor E2-related factor 2. Cancer Research, 66(16), 8293-8296.
Zheng, Y., Ji, X., Ji, K., \& Wang, B. (2015). Hydrogen sulfide prodrugs-A review. Acta Pharmaceutica Sinica B, 5(5), 367-377.

How to cite this article: Lucarini E, Micheli L, Trallori E, et al. Effect of glucoraphanin and sulforaphane against chemotherapy-induced neuropathic pain: Kv7 potassium channels modulation by $\mathrm{H}_{2} \mathrm{~S}$ release in vivo. Phytotherapy Research. 2018;32:2226-2234. https://doi.org/10.1002/ptr.6159 